\section{Crossed Fibrillar' Structure of Plant Cell Walls}

THE so-called 'crossed fibrillar' structure observed in the walls of some plant cells ${ }^{1,2,3}$ and inferred in a variety of others 4 still awaits explanation, and although the evidence for its presence in the latter cases can scarcely be considered satisfactory ${ }^{5}$, this type of structure is sufficiently widespread to present a problem of the first magnitude in cell-wall physics. Several attempts have been made in these columns and elsewhere to define the underlying mechanism, and it is the purpose of this note to point out a new possibility which arises from the recent work of Astbury and Bell' ${ }^{6}$. The importance of the organization of the protoplasmic surface in considerations of wall structure is now slowly being realized, and recent evidence ${ }^{1}$ suggests that it is in this surface that we are to seek the mechanism involved in the regular alternation of chain orientation implied by the crossed fibrillar structure. Now in the recent emendation put forward by Astbury and Bell of what may be called the 'classical' model of protein structure, the fibrous proteins keratin and myosin are considered always to be effectively in the $\beta$-configuration whatever the state of folding [see Figs. 1, 2 and 3, p. 698 of this issue for diagrams of the $\alpha$ - and $\beta$-configurations; the supercontracted form would resemble the diagram given by Astbury and Bell for the globular proteins]. The contraction of the $\alpha$ - or of the $\beta$ - form to the supercontracted condition now corresponds in this model to an effective rotation of the constituent protein chains to the transverse direction.

This type of folding surely gives expression to an underlying principle common to all proteins, including those in the cytoplasm-wall interface, and if we adopt the assumption now being formulated vaguely by some workers that the cellulose chains in a new layer may be oriented in a direction governed by the underlying protein chains, we have a ready solution of the present problem. The direction of cellulose chains may be alternated simply by alternate extension and contraction of the protein chain molecules in the protoplasmic surface. Confirmation of this idea will naturally not be easy. No single cell type has yet been worked out in sufficient detail, but evidence derived from a number of sources is already suggestive.

There are reported in the literature a few cases in which the cellulose chains of the primary wall in an elongated cell lie almost transversely and in later walls layers almost longitudinally ${ }^{3}$. Together with this we may put also the various observations that the physical properties of the cytoplasm in meristematic cells are often different from those in cells becoming adult. We have, for example, numerous statements that high metabolic activity is associated

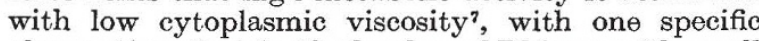
observation that in the hyphæ of Rhizopus (the wall of which is of chitin with a structure closely resembling that of cellulose) the viscosity in the growth zone is much less than elsewhere ${ }^{8}$. Changes in viscosity may, of course, be due to any one of a number of causes, but we do know that in some cases a change in fluidity is associated with changes in the configuration of a protein, for example, with contraction of muscle ${ }^{9}$, and they are precisely what we should expect if, on passing from the meristematic to the adult state, the proteins in the surface are extending. Similarly we have some grounds for thinking that the $p \mathrm{H}$ of cytoplasm in a meristem may not be far removed from the isoelectric point of its constituent proteins ${ }^{10}$, whereas in adult cells it lies near the point of neutrality. It is well known that proteins are $p \mathrm{H}$ sensitive and that in some cases $p \mathrm{H}$ change, though not the causative factor, is associated with muscular contraction ${ }^{8}$.

The contraction and extension of tho protein chains is naturally to be considered as occurring, or at least being initiated, locally; it has no effect on the external appearance of the cell, the shape of which continues to be controlled by the surrounding cellulose envelope. It is difficult to be precise at this stage, particularly with cells like Valonia, Chætomorpha and Cladophora, where the crossed fibrillar structure manifests itself most markedly. It may be significant that changes in cytoplasmic viscosity often accompany nuclear division.

Department of Botany,

R. D. Preston.

University of Leeds.

May 1.

${ }^{1}$ Astbury and Preston, Proc. Roy. Soc., B, 129, 54 (1940)

Preston and Astbury, Proc. Roy. Soc., B, 122, 76 (1937); Nicolai

and Frey-Wyssling, Protoplasma, 30, 403 (1938); Preston, Ann. and Frey-W ysshing, Protoplas
Bot., (N.S.) 3, 507 (1939).

"van Iterson, Protoplasma, 27, 190 (1937); Anderson and Kerr, Ind. Eng. Chem., 30, 48 (1938).

- Freudenberg and Durr, "Kleins Handbuch der Pflanzenanalyse", 3, 142 (1932); Bailey and Kerr, J. Arnold Arbor., 16, 273 (1935).

${ }^{5}$ Preston, Proc. Leeds Phil. Soc., 3, 546 (1939) ; Biol. Rev., 14, 281 (1939).

- Astbury and Bell, Nature [p. 696 of this issue].

"Frey-Wyssling, "Submik. Morphol. des Protoplasmas und seiner Derivate" (Berlin, 1938); Guillermond, "Traité de Cytologie vegetale" (1933) : 'Seifriz, "Protoplasm" (New York and London, 1936).

${ }^{8}$ Guillermond, loc. cit ${ }^{5}$.

- Frey-Wyssling, loc. cit.".

10 Pearsall and Priestley, New Phyt., 22-3, 185 (1923).

\section{Chemical Substitutes for Dietary Protein}

THE stimulating article by Dr. Benesch on the utilization of non-protein nitrogenous compounds as protein substitutes which was recently published in NATURE ${ }^{1}$ is a timely contribution to an important subject. At the outset, Dr. Benesch explains that his object in writing the article is to show that "the problem has reached a practical stage". This opinion is, however, by no means shared by all those who have studied the voluminous literature on the subject published (mainly from the Continent) during the past twenty years. In fact the attitude of Krebs, who reviewed the subject exhaustively in 1937, is in many respects diametrically opposed to that of Dr. Benesch. Moreover, it is all too frequently found that the same set of results is accorded entirely opposite interpretations according to the particular outlook of the workers concerned.

In view of this conflict of opinion, and having in mind the probable war-time shortage of feeding-stuffs, a group of research workers at the Hannah Institute began, about two years ago, a series of experiments designed to reinvestigate the value of urea and ammonium salts as protein substitutes for milk production. An endeavour was made to plan the details of the experiments with sufficient care to ensure that the final results would not readily lend themselves to alternative interpretations, due to the inclusion of inadequate controls or to the recording of incomplete experimental data.

The programme of work finally adopted was twofold. In the first section of the work lactating cows 